\title{
Lifetime-tunable organic persistent room- temperature phosphorescent salts for large-area security printing
}

\author{
Pengfei She ${ }^{1}$, Yanyan Qin ${ }^{1}$, Yun $\mathrm{Ma}^{1 *}$, Feiyang $\mathrm{Li}^{1}$, Jinyu $\mathrm{Lu}^{1}$, Peiling Dai ${ }^{1}$, Hao $\mathrm{Hu}^{1}$, Xiangjie Liu ${ }^{1}$, \\ Shujuan Liu ${ }^{1}$, Wei Huang ${ }^{1,2^{*}}$ and Qiang Zhao ${ }^{1^{*}}$
}

\begin{abstract}
Organic persistent room-temperature phosphorescent (RTP) materials are promising for applications requiring the secure recording and anti-counterfeiting features owing to their appealing optical properties. Several critical challenges, such as the difficulty to obtain high-quality patterns over large areas and low security levels, need to be addressed to meet the requirements for commercial purpose. Here, we prepared a series of quaternary phosphonium salts with different alkyl chains, which showed interesting organic persistent RTP. The ionic characteristics and the alkyl chains of these molecules impart abundant weak intermolecular interactions. This confers the molecules a high crystallinity, which helps to preserve the persistent RTP properties and cover large areas. Moreover, the RTP lifetime of these organic salts varies over a wide range (1.27 to $884.71 \mathrm{~ms})$ and can be tuned by simply changing the alkyl chain length and counterions, which opens new possibilities in multi-level information encryption applications. It is believed that the engineering of organic salts with tunable persistent RTP lifetimes and large-area printing can promote early-stage demonstrations of security applications into mature commercialization.
\end{abstract}

Keywords: persistent room-temperature phosphorescence, organic salts, tunable lifetime, large-area processability, security printing

\section{INTRODUCTION}

Recently, anti-counterfeiting and security data storage technologies have played an important role in different areas. In this context, numerous of luminescent materials have been designed and prepared to achieve security applications. Among them, inorganic nanoparticles with tunable optical properties have been widely developed for achieving anti-counterfeiting applications [1]. In addition to inorganic nanoparticles, organic luminescent molecules also have great potential in security applications due to their low cost, easy molecular structure modification, and tunable excited-states. Particularly, organic persistent room-temperature phosphorescent (RTP) materials that show an observable afterglow have drawn wide research interest due to their unique photophysical processes [24]. To date, remarkable progress has been made in the design and synthesis of organic persistent RTP luminophores through different strategies, including crystalline inducement [5-10], host-guest doping [11,12] and metal-organic framework construction [13]. These approaches provide a rigid environment via intermolecular interactions, which restrict the molecular motions to suppress the non-radiative transition and prevent quenching by atmospheric oxygen [14-17]. The appealing optical properties of these luminophores show great potential in diverse optoelectronic and biomedical areas $[18,19]$, particularly for the information secure encryption and anti-counterfeiting [20,21]. However, the processability of the persistent RTP luminophores still remains challenging because of the strict conditions required for the formation of the crystalline state, which

\footnotetext{
${ }^{1}$ Key Laboratory for Organic Electronics and Information Displays \& Jiangsu Key Laboratory for Biosensors, Institute of Advanced Materials (IAM), Nanjing University of Posts and Telecommunications (NUPT), Nanjing 210023, China

${ }^{2}$ Frontiers Science Center for Flexible Electronics (FSCFE), MIIT Key Laboratory of Flexible Electronics (KLoFE), Shaanxi Key Laboratory of Flexible Electronics, Xi'an Key Laboratory of Flexible Electronics, Xi'an Key Laboratory of Biomedical Materials \& Engineering, Xi'an Institute of Flexible Electronics, Institute of Flexible Electronics (IFE), Northwestern Polytechnical University, Xi'an 710072, China

* Corresponding authors (emails: iamyma@njupt.edu.cn (Ma Y); iamqzhao@njupt.edu.cn (Zhao Q); provost@nwpu.edu.cn (Huang W))
} 
confines most information encryption and anti-counterfeiting of these luminophores to an early proof-of-concept stage [9,22-27]. Consequently, the quality of the created security labels is often rough and their production over a large area is very difficult (Table S1). For example, double information security could be realized by using RTP crystals with dynamic phosphorescence [23]. Anticounterfeiting stamps can be created by freehand writing with RTP materials [24]. Our group has demonstrated the generation of excitation wavelength-dependent multicolor anti-counterfeiting tags via the screen painting technology [25]. In addition, information encryption using persistent RTP materials often reveals different information with and without UV excitation. The encrypted information has a low complexity and can be easily deciphered. These limitations make organic persistent RTP luminophores hardly potential candidates for mass commercial purpose. Therefore, the development of organic persistent RTP luminophores which can be used for large-area security printing is of prime scientific and industrial importance.

Printable organic persistent RTP luminophores are promising to produce high-quality patterns over large area, and the development of molecules with a high crystallinity is a worthy way for large-area printing. Generally, organic salts have high crystallinity because of the intense electrostatic and intermolecular interactions that support the ordered arrangement of the molecules. Additionally, they often have a good solubility in environment-friendly solvents like water and ethanol. Consequently, organic salts with high crystallinity feature a promising approach to produce persistent RTP security tags over large areas.

Organic tetraphenylphosphonium (TPP) salts with persistent RTP possess high quantum efficiency due to the proximity-induced intermolecular electronic coupling in the crystals $[28,29]$. In this study, we developed a series of organic quaternary phosphonium bromide salts with one phenyl group replaced by different alkyl chains. Notably, the alkyl chains and the ionic characteristic of those molecules impart abundant weak intermolecular interactions like $\mathrm{CH} \cdots \pi$ and $\mathrm{CH} \cdots \mathrm{Br}$ that allow the easy crystallization. As a result, their crystalline lattice can tolerate external perturbations very well. In addition, the molecular steric configuration and packing patterns of these organic ionic crystals can be fine-tuned by varying the alkyl chain length, which would give rise to remarkable changes in the decay time of the persistent RTP. The development of luminescent materials with a distinguishable persistent RTP emission but a similar emission color and intensity can achieve high-level information encryption because it can hide the information in multiple-level dimensions [30,31]. In particular, organic quaternary phosphonium bromide salts are promissing candidates to print multi-level information encryption and anti-counterfeiting features over large areas.

\section{EXPERIMENTAL SECTION}

\section{Materials and measurements}

All starting materials and reagents were acquired commercially and further purified by column chromatography and recrystallization before using. ${ }^{1} \mathrm{H}$ nuclear magnetic resonance (NMR) $(400 \mathrm{MHz})$ and ${ }^{13} \mathrm{C}$ NMR $(100 \mathrm{MHz})$ spectra were recorded on a Bruker ACF400 spectrometer at $298 \mathrm{~K}$ using dimethylsulfoxide (DMSO)$\mathrm{d}_{6}$ solvents. Gel filtration chromatography was conducted using a ZORBAX SB-C18 column (Agilent) conjugated to an Agilent 1260 Infinite HPLC system, with the absorption wavelength of $260 \mathrm{~nm}$. The steady-state fluorescence and phosphorescence spectra were measured using $\mathrm{Hi}-$ tachi F-4700. The time-resolved emission spectra were carried out on an Edinburgh Instrument FLS980. Photoluminescence (PL) quantum efficiency was determined by using Edinburgh FLS980 spectrometer with the integrating sphere (142 $\mathrm{mm}$ in diameter) under ambient condition, and the fluorescence and phosphorescence quantum efficiencies $\left(\Phi_{\mathrm{F}}\right.$ and $\left.\Phi_{\mathrm{P}}\right)$ were calculated through the following formulas:

$\Phi_{\mathrm{P}}=\Phi_{\mathrm{E}} \times A_{\mathrm{P}} / A_{\mathrm{E}}$,

$\Phi_{\mathrm{F}}=\Phi_{\mathrm{E}}-\Phi_{\mathrm{P}}$

where $\Phi_{\mathrm{E}}$ refers to the measured total emission quantum efficiency, and $A_{\mathrm{P}}$ and $A_{\mathrm{E}}$ refer to the integral areas of phosphorescence and PL components in PL spectra, respectively. The powder diffraction data were recorded at room temperature on a Rigaku Dmax 2000. Single crystal $\mathrm{X}$-ray diffraction (XRD) data were achieved using graphite-monochromated Mo Ka radiation $(\lambda=0.71073 \AA)$ on a Bruker APEX DUO diffractometer. The collected frames were processed with the software APEX3 and an absorption correction (SADABS) was applied to the collected reflections. The structure was solved by the Olex2 in conjunction with standard difference Fourier techniques and subsequently refined by full-matrix least-squares analyses on $\mathrm{F}_{2}$. The X-ray crystallographic coordinates for structures reported in this study had been deposited at the Cambridge Crystallographic Data Centre (CCDC). These data can be obtained free of charge from the Cambridge Crystallographic Data Centre via www.ccdc. cam.ac.uk/structures. 


\section{Syntheses of TPP bromide salts}

Triphenylphosphine $(5 \mathrm{~g}, 19.0 \mathrm{mmol})$ and 1-bromopropane $(1.74 \mathrm{~mL}, 19.0 \mathrm{mmol})$, were mixed in dry $\mathrm{N}, \mathrm{N}$-dimethyl foramide (DMF) $(15 \mathrm{~mL})$, stirred and refluxed at $120^{\circ} \mathrm{C}$ for $48 \mathrm{~h}$ under nitrogen atmosphere. Then the solvent was removed in vacuum. The product [TPP$\mathrm{C} 3]^{+} \mathrm{Br}^{-}$was purified by silica gel chromatograph using dichloromethane and methanol and recrystallization.

${ }^{1} \mathrm{H}$ NMR (400 MHz, DMSO, $\left.\delta\right): ~ 7.92-7.88 ~(m, 3 H)$, 7.85-7.75 (m, 12H), 3.64-3.57 (m, 2H), 1.62-1.50 (m, $2 \mathrm{H}), 1.09-1.05(\mathrm{~m}, 3 \mathrm{H}) .{ }^{13} \mathrm{C}$ NMR (100 MHz, DMSO, $\left.\delta\right)$ : $134.90\left(\mathrm{~d},{ }^{4} J_{31 \mathrm{P}-13 \mathrm{C}}=2.9 \mathrm{~Hz}\right), 133.66\left(\mathrm{~d},{ }^{3} J_{31 \mathrm{P}-13 \mathrm{C}}=9.9 \mathrm{~Hz}\right)$, $130.30\left(\mathrm{~d},{ }^{2} J_{31 \mathrm{P}-13 \mathrm{C}}=12.3 \mathrm{~Hz}\right), 118.71\left(\mathrm{~d},{ }^{1} J_{31 \mathrm{P}-13 \mathrm{C}}=\right.$ $85.1 \mathrm{~Hz}), 22.18\left(\mathrm{~d},{ }^{1} J_{31 \mathrm{P}-13 \mathrm{C}}=49.3 \mathrm{~Hz}\right), 15.77\left(\mathrm{~d},{ }^{2} J_{31 \mathrm{P}-13 \mathrm{C}}=\right.$ $18.2 \mathrm{~Hz}), 15.00\left(\mathrm{~d},{ }^{3} \mathrm{~J}_{31 \mathrm{P}-13 \mathrm{C}}=4.1 \mathrm{~Hz}\right)$. Elemental analysis for $\mathrm{C}_{21} \mathrm{H}_{22} \mathrm{BrP}$ : C (65.42), $\mathrm{H}$ (5.78).

[TPP-C4] ${ }^{+} \mathrm{Br}^{-}$, [TPP-C5] ${ }^{+} \mathrm{Br}^{-}$and [TPP-C6 $]^{+} \mathrm{Br}^{-}$were obtained by the same method as for [TPP-C3] ${ }^{+} \mathrm{Br}$. [TPP$\mathrm{C} 1]^{+} \mathrm{Br}^{-},[\mathrm{TPP}-\mathrm{C} 2]^{+} \mathrm{Br}^{-}$and $[\mathrm{TPP}-\mathrm{C} 4]^{+} \mathrm{Br}^{-}$were collected by column chromatography and recrystallization of purchased products. Other phosphonium chlorides or iodides were also achieved by the above two methods.

[TPP-C1 ${ }^{+} \mathrm{Br}^{-},{ }^{1} \mathrm{H}$ NMR (400 MHz, DMSO, $\delta$ ): 7.92$7.87(\mathrm{~m}, 3 \mathrm{H}), 7.86-7.75(\mathrm{~m}, 12 \mathrm{H}), 3.21-3.16(\mathrm{~m}, 3 \mathrm{H}) .{ }^{13} \mathrm{C}$ NMR (100 MHz, DMSO, $\delta): 134.83\left(\mathrm{~d},{ }^{4} J_{31 \mathrm{P}-13 \mathrm{C}}=2.9 \mathrm{~Hz}\right)$, $133.30\left(\mathrm{~d},{ }^{3} J_{31 \mathrm{P}-13 \mathrm{C}}=10.7 \mathrm{~Hz}\right), 130.16\left(\mathrm{~d},{ }^{2} J_{31 \mathrm{P}-13 \mathrm{C}}=\right.$ $12.6 \mathrm{~Hz}), 120.35\left(\mathrm{~d},{ }^{1} J_{31 \mathrm{P}-13 \mathrm{C}}=87.7 \mathrm{~Hz}\right), 7.59\left(\mathrm{~d},{ }^{1} J_{31 \mathrm{P}-13 \mathrm{C}}=\right.$ $55.2 \mathrm{~Hz}$ ). Elemental analysis for $\mathrm{C}_{19} \mathrm{H}_{18} \mathrm{BrP}: \mathrm{C}(63.70), \mathrm{H}$ (5.12).

[TPP-C2] ${ }^{+} \mathrm{Br}^{-},{ }^{1} \mathrm{H}$ NMR (400 MHz, DMSO, $\left.\delta\right): 7.93-$ $7.88(\mathrm{~m}, 3 \mathrm{H}), 7.86-7.75(\mathrm{~m}, 12 \mathrm{H}), 3.71-3.62(\mathrm{~m}, 2 \mathrm{H})$, 1.26-1.17 (m, 3H). ${ }^{13} \mathrm{C}$ NMR (100 MHz, DMSO, $\left.\delta\right)$ : $134.90\left(\mathrm{~d},{ }^{4} J_{31 \mathrm{P}-13 \mathrm{C}}=2.9 \mathrm{~Hz}\right), 133.66\left(\mathrm{~d},{ }^{3} J_{31 \mathrm{P}-13 \mathrm{C}}=9.9 \mathrm{~Hz}\right)$, $130.30\left(\mathrm{~d},{ }^{2} J_{31 \mathrm{P}-13 \mathrm{C}}=85.2 \mathrm{~Hz}\right), 118.71\left(\mathrm{~d},{ }^{1} J_{31 \mathrm{P}-13 \mathrm{C}}=\right.$ $85.2 \mathrm{~Hz}), 14.69\left(\mathrm{~d},{ }^{1} J_{31 \mathrm{P}-13 \mathrm{C}}=50.8 \mathrm{~Hz}\right), 6.27\left(\mathrm{~d},{ }^{2} J_{31 \mathrm{P}-13 \mathrm{C}}=\right.$ $5.2 \mathrm{~Hz}$ ). Elemental analysis for $\mathrm{C}_{20} \mathrm{H}_{20} \mathrm{BrP}: \mathrm{C}(64.69), \mathrm{H}$ (5.40).

[TPP-C4 ${ }^{+} \mathrm{Br}^{-},{ }^{1} \mathrm{H}$ NMR (400 MHz, DMSO, $\left.\delta\right): 7.93-$ $7.88(\mathrm{~m}, 3 \mathrm{H}), 7.84-7.75(\mathrm{~m}, 12 \mathrm{H}), 3.63-3.56(\mathrm{~m}, 2 \mathrm{H})$, $1.51-1.46(\mathrm{~m}, 4 \mathrm{H}), 0.90-0.87(\mathrm{t}, J=7 \mathrm{~Hz}, 3 \mathrm{H}) .{ }^{13} \mathrm{C} \mathrm{NMR}$ $(100 \mathrm{MHz}, \mathrm{DMSO}, \delta): 134.88\left(\mathrm{~d},{ }^{4} J_{31 \mathrm{P}-13 \mathrm{C}}=2.8 \mathrm{~Hz}\right)$, $133.63\left(\mathrm{~d},{ }^{3} J_{31 \mathrm{P}-13 \mathrm{C}}=10.0 \mathrm{~Hz}\right), 130.29\left(\mathrm{~d},{ }^{2} J_{31 \mathrm{P}-13 \mathrm{C}}=\right.$ $12.3 \mathrm{~Hz}), 119.01\left(\mathrm{~d},{ }^{1} J_{31 \mathrm{P}-13 \mathrm{C}}=85.2 \mathrm{~Hz}\right), 23.85\left(\mathrm{~d},{ }^{3} J_{31 \mathrm{P}-13 \mathrm{C}}\right.$ $=4.4 \mathrm{~Hz}), 23.21\left(\mathrm{~d},{ }^{2} J_{31 \mathrm{P}-13 \mathrm{C}}=17.1 \mathrm{~Hz}\right), 20.26\left(\mathrm{~d},{ }^{1} J_{31 \mathrm{P}-13 \mathrm{C}}\right.$ $=49.5 \mathrm{~Hz}), 13.28$. Elemental analysis for $\mathrm{C}_{22} \mathrm{H}_{24} \mathrm{BrP}: \mathrm{C}$ (66.11), H (6.08).

[TPP-C5] ${ }^{+} \mathrm{Br}^{-},{ }^{1} \mathrm{H}$ NMR $(400 \mathrm{MHz}, \mathrm{DMSO}, \delta): 7.92-$ $7.75(\mathrm{~m}, 15 \mathrm{H}), 3.66-3.59(\mathrm{~m}, 2 \mathrm{H}), 1.57-1.40(\mathrm{~m}, 4 \mathrm{H})$, $1.33-1.24(\mathrm{~m}, 2 \mathrm{H}), 0.82-0.78(\mathrm{t}, J=7.2 \mathrm{~Hz}, 3 \mathrm{H}) .{ }^{13} \mathrm{C} \mathrm{NMR}$ $(100 \mathrm{MHz}, \mathrm{DMSO}, \delta): 134.85\left(\mathrm{~d},{ }^{4} J_{31 \mathrm{P}-13 \mathrm{C}}=2.8 \mathrm{~Hz}\right)$, $133.62\left(\mathrm{~d},{ }^{3} J_{31 \mathrm{P}-13 \mathrm{C}}=10.0 \mathrm{~Hz}\right), \quad 130.27 \quad\left(\mathrm{~d},{ }^{2} J_{31 \mathrm{P}-13 \mathrm{C}}=\right.$ $12.3 \mathrm{~Hz}), 118.99\left(\mathrm{~d},{ }^{1} J_{31 \mathrm{P}-13 \mathrm{C}}=85.1 \mathrm{~Hz}\right), 31.96\left(\mathrm{~d},{ }^{2} J_{31 \mathrm{P}-13 \mathrm{C}}\right.$ $=16.4 \mathrm{~Hz}), 21.45\left(\mathrm{~d},{ }^{3} J_{31 \mathrm{P}-13 \mathrm{C}}=4.2 \mathrm{~Hz}\right), 21.27,20.37(\mathrm{~d}$, $\left.{ }^{1} J_{31 \mathrm{P}-13 \mathrm{C}}=49.4 \mathrm{~Hz}\right)$, 13.59. Elemental analysis for $\mathrm{C}_{23} \mathrm{H}_{26} \mathrm{BrP}: \mathrm{C}$ (66.79), $\mathrm{H}(6.28)$.

[TPP-C6] ${ }^{+} \mathrm{Br}^{-},{ }^{1} \mathrm{H}$ NMR $(400 \mathrm{MHz}, \mathrm{DMSO}, \delta): 7.92-$ $7.75(\mathrm{~m}, 15 \mathrm{H}), 3.64-3.57(\mathrm{~m}, 2 \mathrm{H}), 1.55-1.42(\mathrm{~m}, 4 \mathrm{H})$, 1.29-1.16 (m, 4H), $0.84-0.80 \quad(\mathrm{~m}, \quad 3 \mathrm{H}) .{ }^{13} \mathrm{C} \quad \mathrm{NMR}$ $(100 \mathrm{MHz}, \mathrm{DMSO}, \delta): 134.86\left(\mathrm{~d},{ }^{4} J_{31 \mathrm{P}-13 \mathrm{C}}=2.5 \mathrm{~Hz}\right)$, $133.63\left(\mathrm{~d},{ }^{3} J_{31 \mathrm{P}-13 \mathrm{C}}=10.0 \mathrm{~Hz}\right), 130.28\left(\mathrm{~d},{ }^{2} J_{31 \mathrm{P}-13 \mathrm{C}}=\right.$ $12.3 \mathrm{~Hz}), 119.00\left(\mathrm{~d},{ }^{1} J_{31 \mathrm{P}-13 \mathrm{C}}=85.0 \mathrm{~Hz}\right), 30.29,29.54(\mathrm{~d}$, $\left.{ }^{3} J_{31 \mathrm{P}-13 \mathrm{C}}=16.4 \mathrm{~Hz}\right), 21.78,21.73\left(\mathrm{~d},{ }^{2} J_{31 \mathrm{P}-13 \mathrm{C}}=4.4 \mathrm{~Hz}\right)$, $20.42\left(\mathrm{~d},{ }^{1} J_{31 \mathrm{P}-13 \mathrm{C}}=49.8 \mathrm{~Hz}\right), 13.79$. Elemental analysis for $\mathrm{C}_{24} \mathrm{H}_{28} \mathrm{BrP}: \mathrm{C}$ (67.39), $\mathrm{H}$ (6.51).

\section{Preparation of security inks}

Organic phosphonium salts ( $2 \mathrm{~g}$ ) were weighed accurately in $15-\mathrm{mL}$ centrifuge tubes. Then, these organic phosphonium salts were dissolved in $10 \mathrm{~mL}$ of ethanol solution. Next, one empty black cartridge can be injected with about $8 \mathrm{~mL}$ of phosphonium salts in ethanol solution.

\section{Theoretical calculation methods}

The computational models were built from the crystal structure based on the combined quantum mechanics and molecular mechanics (QM/MM) theory. Two-layer ONIOM method was used to calculate the electronic structures using Gaussian 09 package [32]. The central molecule was set as QM part at B3LYP/6-31G(d) level, while the surrounding ones were set as the MM part with the universal force field. The excitation energies of [TPP$\mathrm{C} 1]^{+} \mathrm{Br}^{-}$, [TPP-C2 $]^{+} \mathrm{Br}^{-}$, [TPP-C3 ${ }^{+} \mathrm{Br}^{-}$, and [TPP-C4 $]^{+} \mathrm{Br}^{-}$ were calculated under the optimized geometry of the ground state $\left(\mathrm{S}_{0}\right)$. Spin-orbit coupling (SOC) matrix elements between singlet and triplet states were also calculated by PySOC code [33], using linear-response methods based on the excited-state wave functions obtained from above time-dependent density functional theory (TDDFT) calculations. The evaluation employed Casida-type wave functions and the Breit-Pauli (BP) spin-orbit Hamiltonian with an effective charge approximation

\section{RESULTS AND DISCUSSION}

\section{Materials characterization}

Here, a series of alkyl TPP bromide salts (Fig. 1a), namely [TPP-C1 $]^{+} \mathrm{Br}^{-}, \quad[\text { TPP-C2 }]^{+} \mathrm{Br}^{-}, \quad[\text { TPP-C3 }]^{+} \mathrm{Br}^{-}, \quad$ [TPP$\mathrm{C} 4]^{+} \mathrm{Br}^{-},[\mathrm{TPP}-\mathrm{C} 5]^{+} \mathrm{Br}^{-}$, and [TPP-C6 $]^{+} \mathrm{Br}^{-}$, were obtained from a commercial supplier (J\&K Scientific Ltd.) or via a 

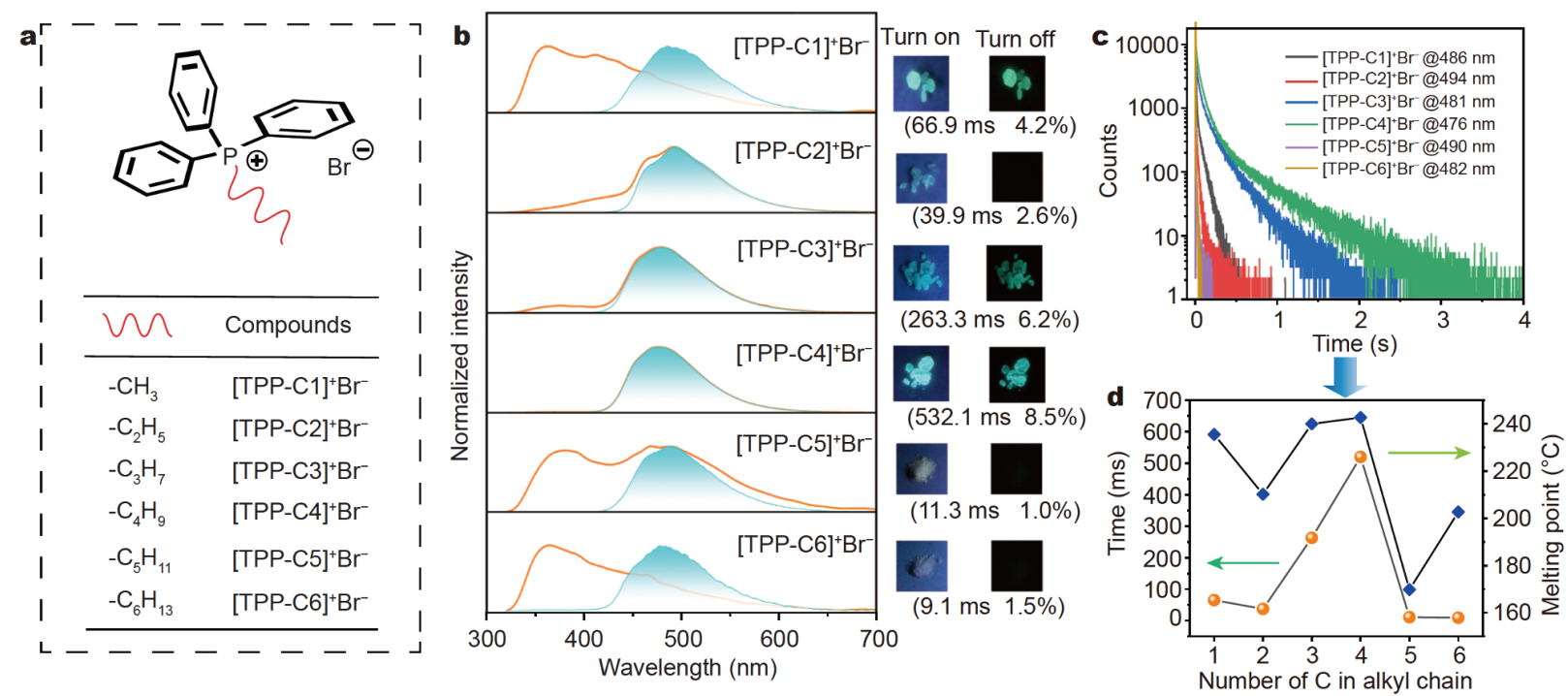

Figure 1 Photophysical properties of TPP bromide salts. (a) The molecular structures of TPP bromides. (b) Steady-state (orange curve) and delayed (green curve, $10 \mathrm{~ms}$ ) PL spectra of organic salts, and the photographs of six organic phosphonium bromides in the crystal state under $300 \mathrm{~nm}$ UV light on and off. (c) Lifetime decay profiles of six organic phosphonium bromides in the crystal state at $298 \mathrm{~K}$. (d) Variation tendency of emission lifetimes (orange points) and melting points (blue points) of six organic salts.

one-step reaction (Scheme S1) to verify our conjecture. Column chromatography and multiple recrystallization were used to further purify the obtained compounds. Their high purity was confirmed by ${ }^{1} \mathrm{H},{ }^{13} \mathrm{C}$, and ${ }^{31} \mathrm{P}$ NMR spectroscopy (Figs S1-S13), high-performance liquid chromatogram spectra (Fig. S14), and single crystal XRD (Tables S2 and S3). The crystals were collected in a dichloromethane/hexane mixture through slow evaporation.

\section{Photophysical properties}

The photophysical properties of these alkyl triphenylphosphonium salts were systematically investigated via the absorption, excitation, steady-state PL, phosphorescence and time decay spectra both in solution and in the solid state. The UV-visible absorption spectra of the organic salts were obtained in the dichloromethane solution $\left(5 \times 10^{-5} \mathrm{~mol} \mathrm{~L}^{-1}\right)$, as shown in Fig. S15. All compounds present similar absorption peaks at 230, 260, 265 and $275 \mathrm{~nm}$, which originate from the intramolecular $\pi-\pi$ or $\pi-\pi^{*}$ transitions. Upon excitation at $260 \mathrm{~nm}$, the prompt emission spectra in solution consist of a main emission band at $380 \mathrm{~nm}$ and a weak band in the $400-450 \mathrm{~nm}$ range with a marked tail at longer emission wavelengths. Almost identical delayed PL spectra were recorded at $77 \mathrm{~K}$ (Fig. S16), and the emission decay time ranges from 1064.5 to $1584.7 \mathrm{~ms}$, which reveals that different alkyl chains have a little impact on the triplet exciton energy level in the single molecule state.

\section{RTP lifetime tuning through alky engineering}

In the solid state, the compounds had distinct PL properties when the alkyl chain length varied, as indicated by the emission spectra and lifetimes in Fig. 1b, c. Under UV irradiation, the alkyl TPP salts have a blue or green emission in ambient air at room temperature. When the UV light was tuned off, a prominent green persistent RTP emission was observed with naked eyes in the ionic crystals of $[\mathrm{TPP}-\mathrm{C} 1]^{+} \mathrm{Br}^{-}, \quad[\mathrm{TPP}-\mathrm{C} 3]^{+} \mathrm{Br}^{-}$and $[\mathrm{TPP}-$ $\mathrm{C} 4]^{+} \mathrm{Br}^{-}$, whereas there was no such emission for [TPP$\mathrm{C} 2]^{+} \mathrm{Br}^{-},[\mathrm{TPP}-\mathrm{C} 5]^{+} \mathrm{Br}^{-}$and [TPP-C6 $]^{+} \mathrm{Br}^{-}$. The emission peak for [TPP-C1 $]^{+} \mathrm{Br}^{-}$is located around $380 \mathrm{~nm}$. When the alkyl length increases from $\mathrm{C} 1$ to $\mathrm{C} 4$, the shortwavelength emission at $380 \mathrm{~nm}$ gradually disappears, but a new emission peak appears at $480 \mathrm{~nm}$. Interestingly, the emission at $380 \mathrm{~nm}$ appears again when the alkyl chains change to C5 and C6. The luminescence lifetimes of the emission peaks around $380 \mathrm{~nm}$ are in the nanosecond scale (Fig. S17), indicating the fluorescence characteristics. In contrast, the emission bands around $480 \mathrm{~nm}$ are phosphorescent because of their long emission lifetimes in the millisecond scale. Clearly, the length of the alkyl chain significantly affects the emission decay time (Fig. 1c, d, Table S4). The delayed PL spectra indicate an identical phosphorescence profile, which suggests that the influence of the alkyl chain length on the triplet excited 
state energy level is insignificant. Additionally, the phosphorescence lifetime of the organic salts is insensitive to the external atmosphere (Fig. S18) given the overlapping spectra obtained under oxygen and argon atmospheres. This is because the rigid crystalline state protects the triplet exciton from oxygen-induced quenching.

Crystal structures in Fig. 2a show the close proximity to each other in these organic salts, suggesting a strong electronic coupling between two adjacent molecules, and such a remarkable electronic coupling is an important factor to achieve RTP properties [29]. As shown in Fig. S19, the intensity of phosphorescence is remarkably enhanced with the increase of concentrations of quaternary phosphonium salts from 0.1 to $5.0 \mathrm{wt} \%$ in polymethylmethacrylate (PMMA), which can also demonstrate that the electronic coupling is an important factor to achieve RTP properties. Moreover, Fig. 2a shows that abundant $\mathrm{CH} \cdots \pi(2.85-2.99 \AA)$ and $\mathrm{CH} \cdots \mathrm{Br}$ interactions (2.84-3.15 $\AA$ ) exist in these crystals. These interactions work together with the electrostatic interactions to restrict the molecular motions in the crystal, reducing the nonradiative transition. In addition, the heavy-atom effect can promote the intersystem crossing rate and boost the phosphorescence emission of these organic salts due to strong SOC. Therefore, the persistent RTP properties of the organic salts can be attributed to the strong intermolecular electronic coupling, abundant intra/inter-molecular interactions and significant heavy-atom effect in the crystals.

To explore the crucial role of the alkyl chains in the regulation of the persistent RTP lifetimes of the quaternary phosphonium salts, we first performed a thermal analysis of the bromide salts. The length of the alkyl chain has a remarkable impact on the melting point of the organic salts. The evolution of the melting point agrees well with the changes in the luminescence lifetime (Fig. 1d), suggesting that the intra- and inter-molecular interactions play an important role in determining the persistent RTP lifetime. Then, the detailed molecular packing of [TPP-C1 $]^{+} \mathrm{Br}^{-}$, [TPP-C2 $]^{+} \mathrm{Br}^{-}$, [TPP-C3] ${ }^{+} \mathrm{Br}^{-}$, and [TPP$\mathrm{C} 4]^{+} \mathrm{Br}^{-}$was carefully analyzed to further understand the tuning mechanism. The side views of the crystals were observed to explore the mechanism for the persistent RTP tuning, as shown in Fig. 2b. The [TPP-C1 $]^{+} \mathrm{Br}^{-}$crystal shows parallelogram lattices with an included angle of $70^{\circ}$, whereas the [TPP-C 3$]^{+} \mathrm{Br}^{-}$and $[\mathrm{TPP}-\mathrm{C} 4]^{+} \mathrm{Br}^{-}$crystals have a larger included angle of $90^{\circ}$. This suggests that different tetragonal lattices are obtained through the engineering of the alkyl chain in the quaternary phosphonium salts. The tighter molecular stacking in [TPP$\mathrm{C} 3]^{+} \mathrm{Br}^{-}$and $[\mathrm{TPP}-\mathrm{C} 4]^{+} \mathrm{Br}^{-}$better restricts molecular motions than in [TPP-C1 $]^{+} \mathrm{Br}^{-}[23,34-36]$, which results in a significant effect on the RTP lifetime. To better understand how the alky chains influence the persistent RTP, the electronic structures of the organic quaternary phosphonium salts in the crystals were studied by molecular dynamics simulation (Fig. S20). QM/MM theory was employed to simulate the photophysical processes of $[\mathrm{TPP}-\mathrm{C} 1]^{+} \mathrm{Br}, \quad[\mathrm{TPP}-\mathrm{C} 2]^{+} \mathrm{Br}, \quad[\mathrm{TPP}-\mathrm{C} 3]^{+} \mathrm{Br}$ and [TPP$\mathrm{C} 4]^{+} \mathrm{Br}$ in the crystals. Two-layer ONIOM method was used to calculate their electronic structures. As shown in Fig. S21, remarkable charge transfer from the bromine to each phosphonium cation was observed, which can reduce the energy gap between excited state $\left(S_{1}\right)$ and triplet excited state $\left(\mathrm{T}_{1}\right)\left(\Delta E_{\mathrm{ST}}\right)$. The $\Delta E_{\mathrm{ST}}$ values of these organic quaternary phosphonium salts were calculated to be

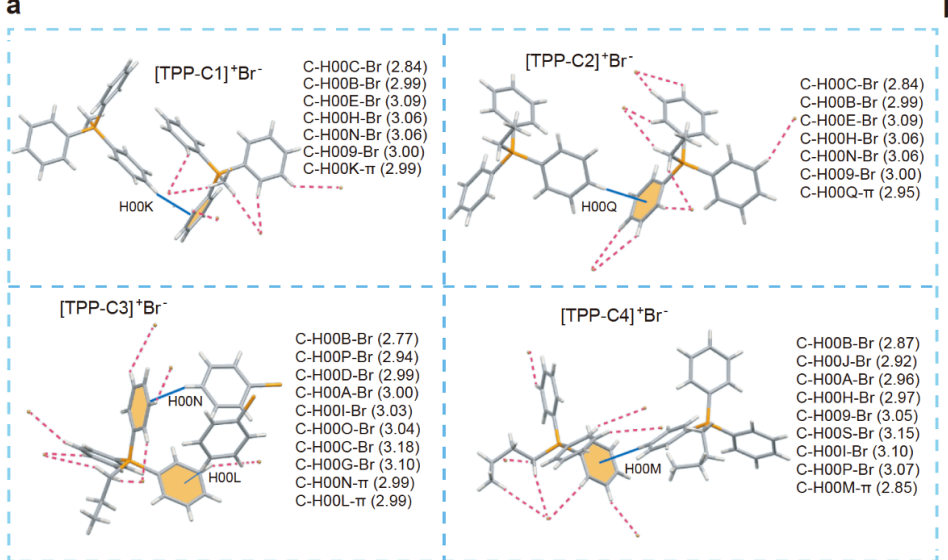

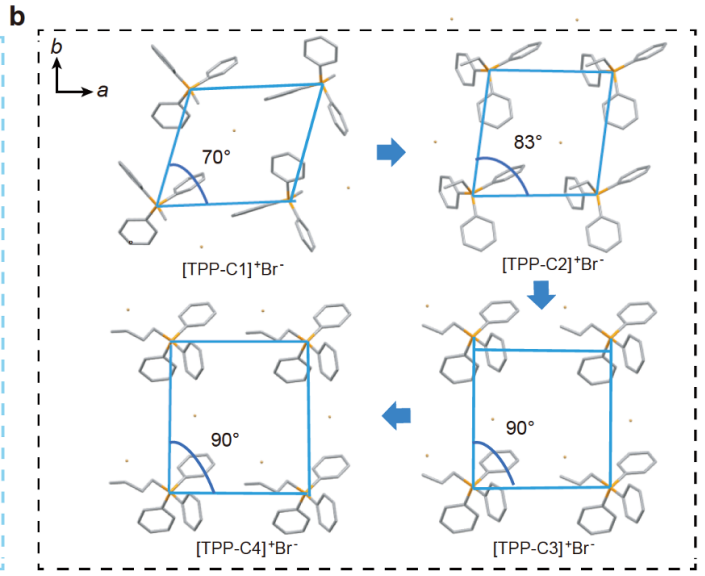

Figure 2 Crystal structures of organic salts. Intermolecular and intramolecular interactions and molecular arrangement in [TPP-C1 $]^{+} \mathrm{Br}^{-},[\mathrm{TPP}-$ $\mathrm{C} 2]^{+} \mathrm{Br}^{-},[\mathrm{TPP}-\mathrm{C} 3]^{+} \mathrm{Br}^{-}$and [TPP-C4$]^{+} \mathrm{Br}^{-}$crystals (distance is in $\AA$ ). 
lower than $0.1 \mathrm{eV}$ (Fig. S22), which is beneficial for promoting intersystem crossing process. Besides, the SOC from $\mathrm{T}_{1}$ to $\mathrm{S}_{0}$ of $[\mathrm{TPP}-\mathrm{C} 2]^{+} \mathrm{Br}$, [TPP-C1 $]^{+} \mathrm{Br}$, [TPP-C3 $]^{+} \mathrm{Br}$ and $[\mathrm{TPP}-\mathrm{C} 4]^{+} \mathrm{Br}$ was calculated to be $82.85,75.68,58.48$, $57.78 \mathrm{~cm}^{-1}$, respectively. The extension of RTP lifetime is because low SOC of $\mathrm{T}_{1}$ to $\mathrm{S}_{0}$ decreases the nonradiative decay rates, and this result is well in accordance with the experimental data (Table S5 and Fig. S23). The differences in SOC of those organic salts can be attributed to different molecular packing and intermolecular interactions caused by various alky chain lengths (Figs $1 \mathrm{~d}$ and 2b). Combined the theoretical calculations with experimental results, the structure-property relationship is clearly revealed.

\section{RTP lifetime tuning through counterions}

Changing the halide anion in the quaternary phosphonium salts also reveals a facile and effective method to tune the persistent RTP lifetime. Herein, we prepared alkyl TPP salts with chloride or iodide counterions and studied their PL properties. For instance, the RTP lifetime of all the organic salts increased when changing the counterion to chloride and the order followed that of the lengths of the alkyl chains (Fig. S24 and Table S6). The analysis of the single-crystals of the quaternary phosphonium iodide salts revealed that their molecular packing was similar to that of the bromide salts (Fig. S25). This indicates that the nature of the halogen ion has a negligible effect on the stacking mode. Besides, when the iodide anions were served as the counterions, the emission decay times substantially decreased following the same order as well. The regulation of the RTP lifetime in the ionic crystals can be explained by different electronic coupling effects of different counterions. Taking [TPP$\mathrm{C} 4]^{+} \mathrm{X}^{-}(\mathrm{X}=\mathrm{Cl}, \mathrm{Br}$ and $\mathrm{I})$ as example, the distances between two phosphorus atoms in the crystals varied from $8.271 \AA \quad\left([\mathrm{TPP}-\mathrm{C} 4]^{+} \mathrm{Cl}^{-}\right)$to $8.435 \AA$ ([TPP-C4 $]^{+} \mathrm{I}^{-}$) (Fig. S26). The short intermolecular distance of [TPP$\mathrm{C} 4]^{+} \mathrm{Cl}^{-}$implied a strong electronic coupling effect, which would promote the generation of persistent RTP [28]. Besides, when the nuclear charge number increases from chlorine to iodine, the higher SOC occurrs, which can increase the nonradiative rate $\left(k_{\mathrm{nr}}\right)$ from $\mathrm{T}_{1}$ to $\mathrm{S}_{0}$, resulting in short phosphorescence lifetime according to $\tau_{\mathrm{p}}=1$ / $\left(k_{\mathrm{nr}}+k_{\mathrm{p}}+k_{\mathrm{q}}\right)\left(k_{\mathrm{q}}\right.$ represents the quenching rate and it can be negligible because its $\mathrm{PL}$ property is insensitive to oxygen) (Fig. S18, Table S5). As a result, the phosphorescence lifetime can be conveniently tuned in a wide range from 1.27 to $884.71 \mathrm{~ms}$ by changing the length of the alkyl chain or the counterion (Tables S4 and S5), suggesting a great potential for multi-level information encryption.

\section{Large-area security printing}

More importantly, [TPP-C1 $]^{+} \mathrm{Br}^{-}$, [TPP-C3 $]^{+} \mathrm{Br}^{-}$, and $[\mathrm{TPP}-\mathrm{C} 4]^{+} \mathrm{Br}^{-}$retain robust persistent $\mathrm{RTP}$ properties upon vigorous mechanical grinding (Fig. $3 \mathrm{a}, \mathrm{b}$ and Fig. S27). The powder XRD patterns of the crystals indicate sharp and intense diffraction peaks that remain strong after grinding while new peaks also emerge (Fig. 3e and Fig. S28). This indicates that the ground samples kept the crystalline lattices because the alkyl chains and the ionic characteristic of these crystals generate many weak intermolecular interactions like $\mathrm{CH} \cdots \pi$ and $\mathrm{CH} \cdots \mathrm{Br}$ interactions to easily trigger crystallization. These interactions make the crystalline lattices very tolerant to external mechanical perturbation. The preservation of the persistent RTP behavior after vigorous grinding indicates dense intra- and inter-molecular interactions. Besides, these organic phosphonium bromides have good photostability, with their emission intensity at around $490 \mathrm{~nm}$ unchanged after 20 cycles (Fig. S29). These features are extraordinarily desirable for applications in large-area processability of persistent RTP materials.

A commercial inkjet printer was used to demonstrate the feasibility to process large areas with the quaternary phosphonium salts prepared. The production security labels made with high-quality patterns are desired for anti-counterfeiting applications (Fig. 3c). The easy crystallization of the quaternary phosphonium salts makes them ideal security inks that can be integrated into commercial inkjet printers for security printing. Fig. 3d shows that a large number of high-resolution patterns could be printed on a A4 filter paper using the [TPP$\mathrm{C} 4]^{+} \mathrm{Br}^{-}$ink $\left(0.2 \mathrm{~g} \mathrm{~mL}^{-1}\right)$. The images are invisible under sunlight but can be clearly visualized under UV light. More importantly, the persistent RTP behavior remained after inkjet printing because of the fine crystals contained in the ink deposited on the paper, as suggested by the $\mathrm{XRD}$ results (Fig. 3e). Consequently, the printed patterns can still be observed by the naked eye after turning off the UV excitation. In addition, the printed security labels show good repeatable ability (Fig. S30). The long-lasting persistent RTP emission affords a higher level of anticounterfeiting features compared with the commonlyused fluorescent security labels.

\section{Multi-level security printing}

In addition, the tunable emission lifetimes of the quaternary phosphonium salts were used to explore the 
a

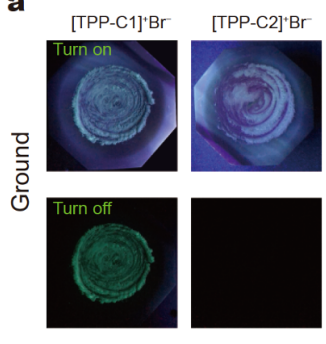

d
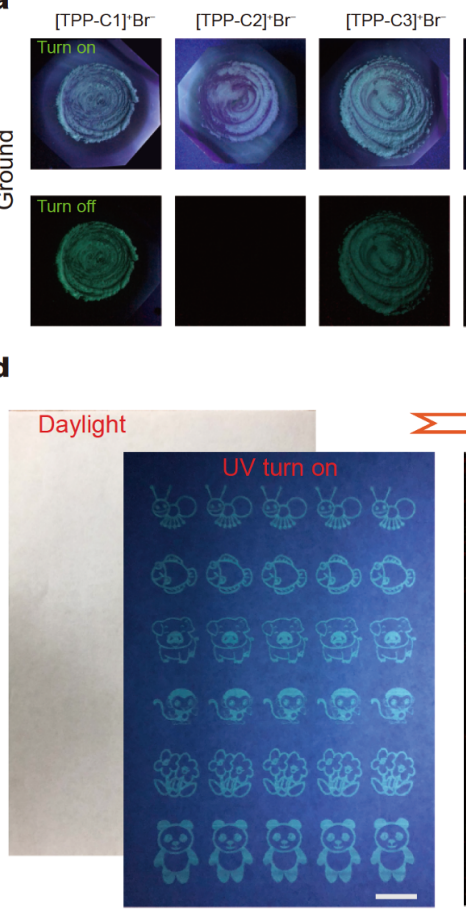

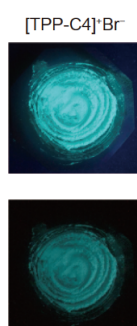

b
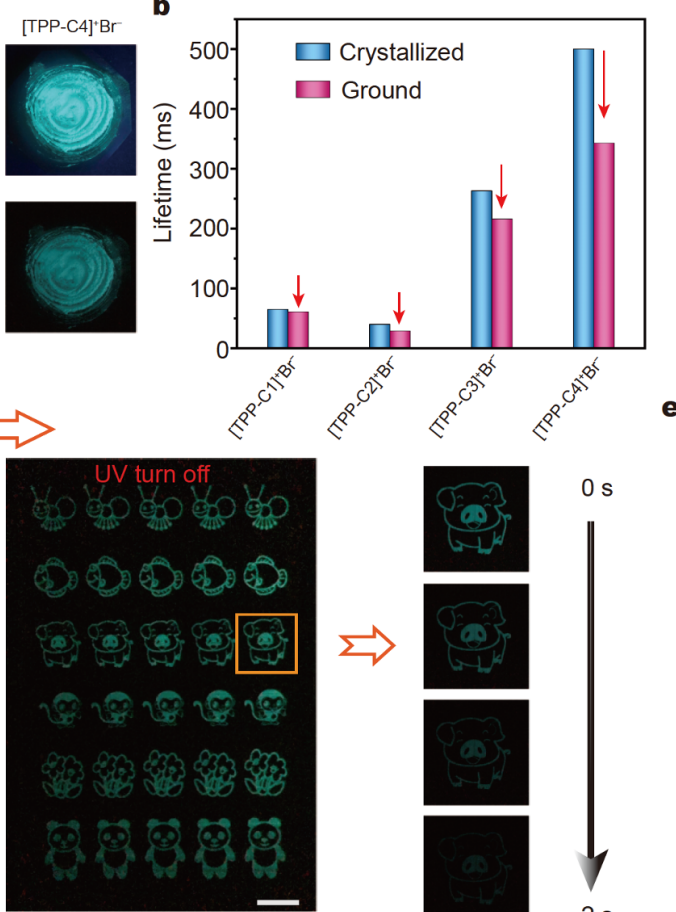

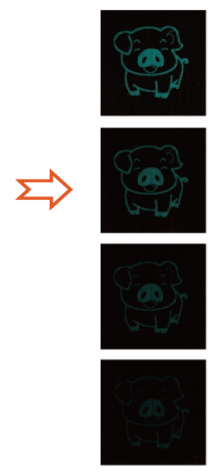

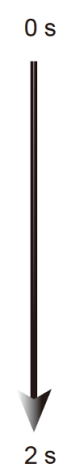

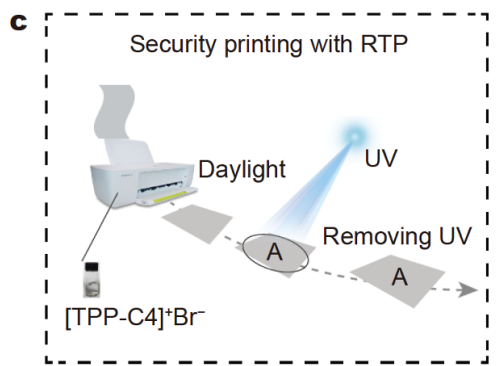

e

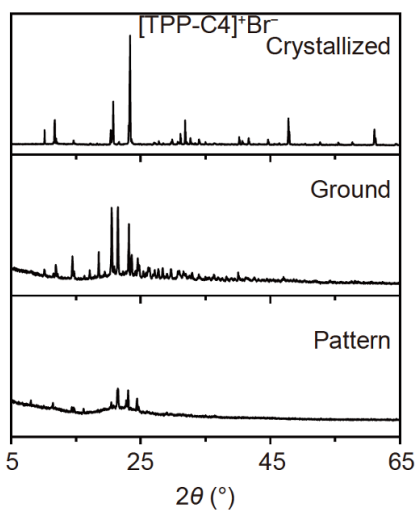

Figure 3 Large-area security printing. (a) Photographs of ground solids at ambient conditions, taken before and after ceasing the $300 \mathrm{~nm} \mathrm{UV}$

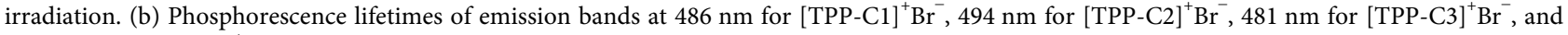
$476 \mathrm{~nm}$ for [TPP-C4] ${ }^{+} \mathrm{Br}^{-}$in crystallized and ground solids at $298 \mathrm{~K}$. (c) Schematic illustration of security printing with RTP. (d) Photographs of animal cartoons and flowers printed on a A4 filter paper by using [TPP-C4] ${ }^{+} \mathrm{Br}^{-}$as the ink under ambient light, UV light and ceasing UV irradiation. Scale bars: $3 \mathrm{~cm}$. (e) XRD of crystallized, ground solids of [TPP-C4] ${ }^{+} \mathrm{Br}^{-}$and printed pattern with [TPP-C4] ${ }^{+} \mathrm{Br}^{-}$.

possibility to generate multi-level information encryption. More specifically, [TPP-C3 $]^{+} \mathrm{Br}^{-}$, [TPP-C4] $]^{+} \mathrm{Br}^{-}$, [TPP$\mathrm{C} 4]^{+} \mathrm{Cl}^{-}$, and a red-emitting complex with a higher quantum efficiency but a much shorter emission lifetime of $717 \mu$ s (Fig. 4a and Fig. S31) were used to create a series of Arabic numerals. After a certain delay, a series of numbers are expected at different points in time due to the distinct lifetime of each part. Fig. $4 \mathrm{~b}$ illustrates how four Arabic numerals " 8888 " with a bright red emission appeared under UV irradiation. The short-lived phosphorescence immediately disappeared after the excitation source was removed and new numbers of " 8998 " with a green emission was observed after $0.2 \mathrm{~s}$. Furthermore, two other groups of Arabic numerals, namely "7349" and " 1314 ", could be read after 0.5 and $1 \mathrm{~s}$, respectively. Therefore, confidential information can be stored in a specific time sequence and several pieces of information can be released at a different time point or create interference to protect the "true" information. Such multilevel information encryption significantly improves the security level of the stored information (Fig. 4c). Multilevel anti-counterfeiting can also be achieved using [TPP-
$\mathrm{C} 3]^{+} \mathrm{Br}^{-}, \quad[\mathrm{TPP}-\mathrm{C} 4]^{+} \mathrm{Br}^{-}$, and $[\mathrm{TPP}-\mathrm{C} 2]_{2}^{+}\left[\mathrm{MnBr}_{4}\right]^{2-}$ as inks. $[\mathrm{TPP}-\mathrm{C} 2]_{2}^{+}\left[\mathrm{MnBr}_{4}\right]^{2-}$ was chosen because it has a similar emission color and intensity but a remarkably shorter emission lifetime of $311 \mu$ s (Fig. S32) than the quaternary phosphonium salts. In Fig. 4d, a night scene photograph was printed using the three inks and showed a green emission under UV excitation. Once the UV lamp is turned off, the stars and the moon immediately vanished because of the short-lived emission of the Mn(II) complex. After a delay of $1.0 \mathrm{~s}$, only the house could be identified by the naked eye. Between the UV irradiation and the removal of the excitation source, the printed security label changed three times, which makes it very difficult to forge. Importantly, the printed security information can be observed and decrypted under ambient conditions for 10 months (Fig. S33), which is quite suitable for security application.

\section{CONCLUSIONS}

In summary, a series of quaternary phosphonium salts with distinct RTP lifetimes from 1.27 to $884.71 \mathrm{~ms}$ that can be printed over large areas were prepared by chan- 

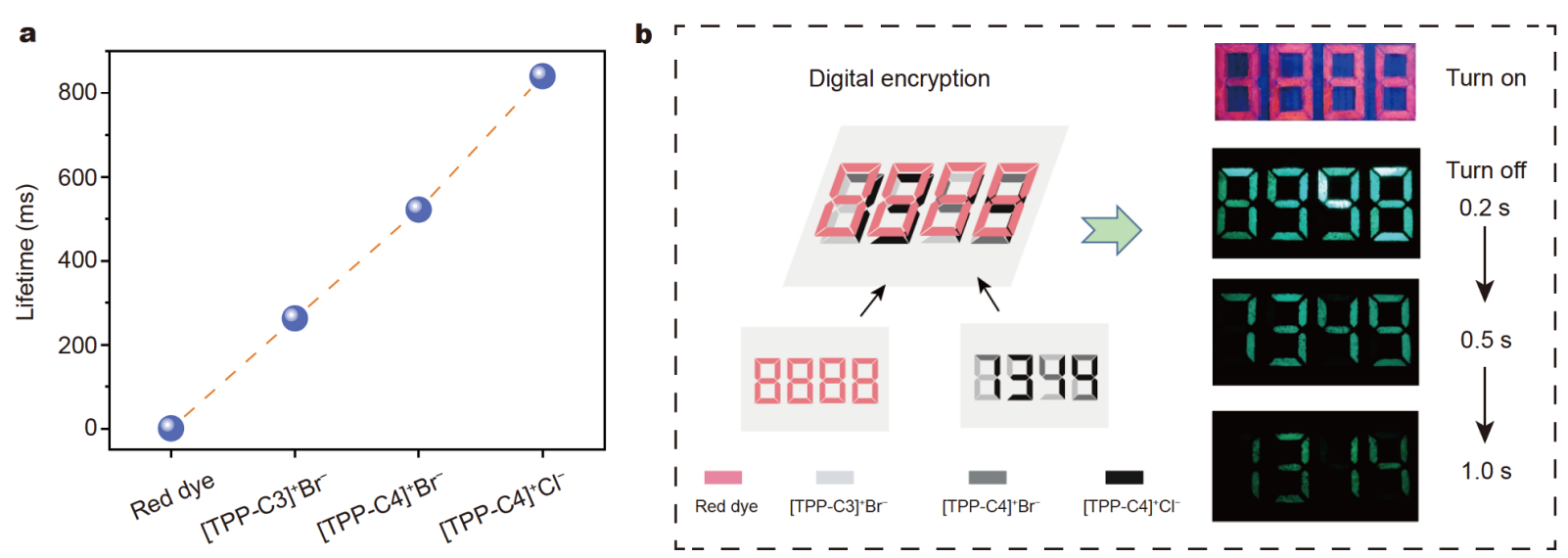

c
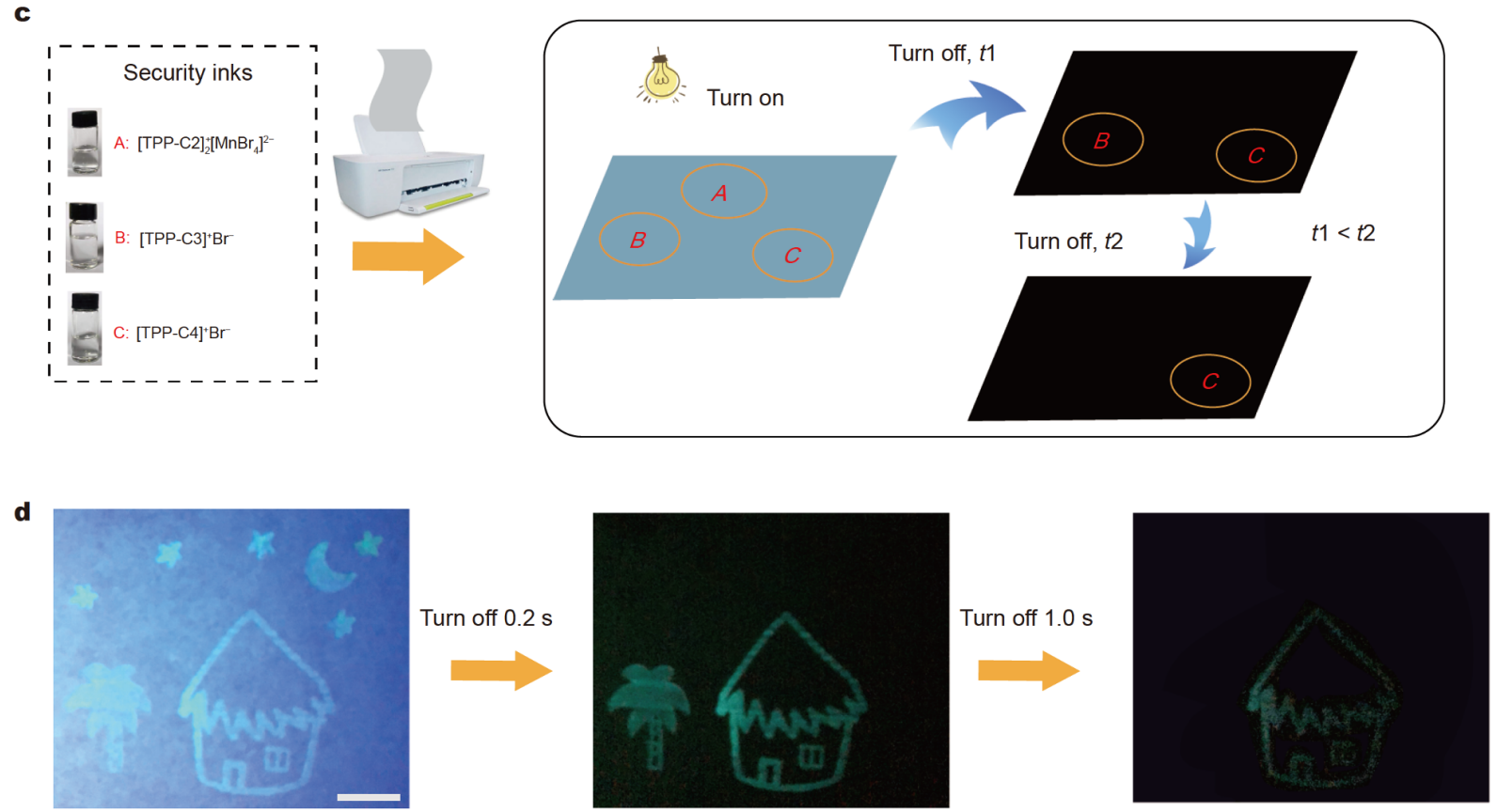

Figure 4 Multi-level security applications. (a) Emission lifetimes of the red dye and three ionic crystals. (b) The time-resolved digital encryption using ionic crystals and red dye as background interference. (c) Schematic illustration of multi-level security printing by three security inks. (d) Photographs of multi-level security information printed by [TPP-C2 $]_{2}^{+}\left[\mathrm{MnBr}_{4}\right]^{2-}$, [TPP-C3 $]^{+} \mathrm{Br}^{-}$and $[\mathrm{TPP}-\mathrm{C} 4]^{+} \mathrm{Br}^{-}$ethanol solution as inks. Scale bars: $3 \mathrm{~cm}$.

ging the alkyl chain length and halide counterion. The organic salts retain a strong persistent RTP emission after mechanical grinding due to the abundant intra- and intermolecular interactions in their structures and their high crystallinity. The molecular interactions in the materials changed as the length of alkyl chain varied, as indicated by the melting point. The interactions are responsible for the tuning of the RTP lifetime. The different effects of the heavy atom for different halide ions also substantially influence the RTP lifetime. The high crystallinity and the tunable persistent RTP properties allow us to use these organic salts for multi-level information encryption and generation of anti-counterfeiting features using a commercial inkjet printer. The results obtained in this study show the feasibility of large-area printing and significant lifetime-tuning of organic persistent RTP salts through rational molecular design, thus paving the way for their mass production and widespread commercial use.

Received 2 September 2020; accepted 16 October 2020; published online 15 January 2021

1 Ren W, Lin G, Clarke C, et al. Optical nanomaterials and enabling technologies for high-security-level anticounterfeiting. Adv Mater, 
2020, 32: 1901430

2 Shoji Y, Ikabata Y, Wang Q, et al. Unveiling a new aspect of simple arylboronic esters: long-lived room-temperature phosphorescence from heavy-atom-free molecules. J Am Chem Soc, 2017, 139: 2728-2733

3 Kenry, Chen C, Liu B. Enhancing the performance of pure organic room-temperature phosphorescent luminophores. Nat Commun, 2019, 10: 2111

4 Hirata S. Recent advances in materials with room-temperature phosphorescence: photophysics for triplet exciton stabilization. Adv Opt Mater, 2017, 5: 1700116

5 An Z, Zheng C, Tao Y, et al. Stabilizing triplet excited states for ultralong organic phosphorescence. Nat Mater, 2015, 14: 685-690

6 Xie Y, Ge Y, Peng Q, et al. How the molecular packing affects the room temperature phosphorescence in pure organic compounds: ingenious molecular design, detailed crystal analysis, and rational theoretical calculations. Adv Mater, 2017, 29: 1606829

7 Li W, Huang Q, Mao Z, et al. Selective expression of chromophores in a single molecule: soft organic crystals exhibiting fullcolour tunability and dynamic triplet-exciton behaviours. Angew Chem Int Ed, 2020, 59: 3739-3745

8 Zhao W, He Z, Lam JWY, et al. Rational molecular design for achieving persistent and efficient pure organic room-temperature phosphorescence. Chem, 2016, 1: 592-602

9 He Z, Gao H, Zhang S, et al. Achieving persistent, efficient, and robust room-temperature phosphorescence from pure organics for versatile applications. Adv Mater, 2019, 31: 1807222

10 Mane SKB, Mu Y, Ubba E, et al. Tuning the organic persistent room-temperature phosphorescence through aggregated states. J Mater Chem C, 2019, 7: 15219-15224

11 Li D, Lu F, Wang J, et al. Amorphous metal-free room-temperature phosphorescent small molecules with multicolor photoluminescence via a host-guest and dual-emission strategy. J Am Chem Soc, 2018, 140: 1916-1923

$12 \mathrm{Ma} \mathrm{X}, \mathrm{Xu} \mathrm{C}, \mathrm{W}$ ang J, et al. Amorphous pure organic polymers for heavy-atom-free efficient room-temperature phosphorescence emission. Angew Chem Int Ed, 2018, 57: 10854-10858

13 Yang X, Yan D. Strongly enhanced long-lived persistent room temperature phosphorescence based on the formation of metalorganic hybrids. Adv Opt Mater, 2016, 4: 897-905

14 Gong Y, Zhao L, Peng Q, et al. Crystallization-induced dual emission from metal- and heavy atom-free aromatic acids and esters. Chem Sci, 2015, 6: 4438-4444

15 Li B, Gong Y, Wang L, et al. Highly efficient organic room-temperature phosphorescent luminophores through tuning triplet states and spin-orbit coupling with incorporation of a secondary group. J Phys Chem Lett, 2019, 10: 7141-7147

16 Bian L, Shi H, Wang X, et al. Simultaneously enhancing efficiency and lifetime of ultralong organic phosphorescence materials by molecular self-assembly. J Am Chem Soc, 2018, 140: 10734-10739

17 She $\mathrm{P}, \mathrm{Yu} \mathrm{Y}$, Qin Y, et al. Controlling organic room temperature phosphorescence through external heavy-atom effect for white light emission and luminescence printing. Adv Opt Mater, 2019, 8: 1901437

18 Zhen X, Tao Y, An Z, et al. Ultralong phosphorescence of watersoluble organic nanoparticles for in vivo afterglow imaging. Adv Mater, 2017, 29: 1606665

19 Wang T, Su X, Zhang X, et al. Aggregation-induced dual-phosphorescence from organic molecules for nondoped light-emitting diodes. Adv Mater, 2019, 31: 1904273
20 Zhou B, Yan D. Hydrogen-bonded two-component ionic crystals showing enhanced long-lived room-temperature phosphorescence via TADF-assisted förster resonance energy transfer. Adv Funct Mater, 2019, 29: 1807599

21 Li H, Li H, Wang W, et al. Stimuli-responsive circularly polarized organic ultralong room temperature phosphorescence. Angew Chem Int Ed, 2020, 59: 4756-4762

22 Cai S, Shi H, Li J, et al. Visible-light-excited ultralong organic phosphorescence by manipulating intermolecular interactions. Adv Mater, 2017, 29: 1701244

23 Yang J, Zhen X, Wang B, et al. The influence of the molecular packing on the room temperature phosphorescence of purely organic luminogens. Nat Commun, 2018, 9: 840

24 Xue $\mathrm{P}$, Wang $\mathrm{P}$, Chen $\mathrm{P}$, et al. Bright persistent luminescence from pure organic molecules through a moderate intermolecular heavy atom effect. Chem Sci, 2017, 8: 6691

$25 \mathrm{Gu} \mathrm{L}$, Shi H, Bian L, et al. Colour-tunable ultra-long organic phosphorescence of a single-component molecular crystal. Nat Photonics, 2019, 13: 406-411

26 Yuan J, Chen R, Tang X, et al. Direct population of triplet excited states through singlet-triplet transition for visible-light excitable organic afterglow. Chem Sci, 2019, 10: 5031-5038

27 Tao Y, Chen R, Li H, et al. Resonance-activated spin-flipping for efficient organic ultralong room-temperature phosphorescence. Adv Mater, 2018, 30: 1803856

28 Chen G, Guo S, Feng H, et al. Anion-regulated transient and persistent phosphorescence and size-dependent ultralong afterglow of organic ionic crystals. J Mater Chem C, 2019, 7: 14535-14542

29 Chen G, Feng H, Feng F, et al. Photophysical tuning of organic ionic crystals from ultralong afterglow to highly efficient phosphorescence by variation of halides. J Phys Chem Lett, 2018, 9: 6305-6311

30 She P, Ma Y, Qin Y, et al. Dynamic luminescence manipulation for rewritable and multi-level security printing. Matter, 2019, 1: 16441655

31 Lu Y, Zhao J, Zhang R, et al. Tunable lifetime multiplexing using luminescent nanocrystals. Nat Photon, 2014, 8: 32-36

32 Frisch MJ, Trucks GW, Schlegel HB, et al. Gaussian 09. Wallingford: Gaussian, Inc., 2009

33 Gao X, Bai S, Fazzi D, et al. Evaluation of spin-orbit couplings with linear-response time-dependent density functional methods. J Chem Theor Comput, 2017, 13: 515-524

34 Hirata S. Roles of localized electronic structures caused by $\pi$ degeneracy due to highly symmetric heavy atom-free conjugated molecular crystals leading to efficient persistent room-temperature phosphorescence. Adv Sci, 2019, 6: 1900410

35 Gu L, Shi H, Gu M, et al. Dynamic ultralong organic phosphorescence by photoactivation. Angew Chem Int Ed, 2018, 57: 84258431

36 Mao Z, Yang Z, Fan Z, et al. The methylation effect in prolonging the pure organic room temperature phosphorescence lifetime. Chem Sci, 2019, 10: 179-184

Acknowledgements We thank the financial support from the National Funds for Distinguished Young Scientists (61825503), the National Natural Science Foundation of China (62075101, 21701087 and 61775101), the National Program for Support of Top-Notch Young Professionals, and the Postgraduate Research \& Practice Innovation Program of Jiangsu Province (46030CX18010). 
Author contributions She P, Ma Y, Zhao Q and Huang W conceived the idea for this paper and designed the experiments. She P and Qin $\mathrm{Y}$ performed the synthesis and security printing experiments. Li F, Lu J, $\mathrm{Hu} \mathrm{H}$, Liu X and Liu S contributed to the implementation of the experiments and measurements. Ma Y, She $\mathrm{P}$ and Zhao $\mathrm{Q}$ analyzed the data and wrote the manuscript. Liu $S$ revised the manuscript and provided some suggestions. All authors discussed the results and commented on the manuscript.

Conflict of interest The authors declare no conflict of interest.

Supplementary information Supporting data are available in the online version of the paper.

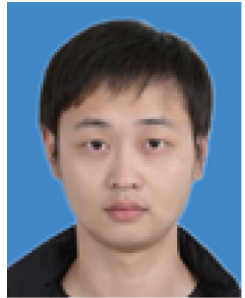

Yun Ma obtained his MSc degree from Nanjing University of Posts and Telecommunications in 2012, under the supervision of Prof. Qiang Zhao and his $\mathrm{PhD}$ degree from Hong Kong Baptist University in 2015, under the supervision of Prof. Wai Yeung Wong. He is currently an associate professor at Nanjing University of Posts and Telecommunications. His research focuses on the development of stimuli-responsive materials for advanced optical applications.

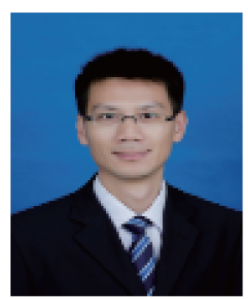

Qiang Zhao received his $\mathrm{PhD}$ degree in 2007 from Fudan University. He then became a postdoctoral fellow at Nagoya University in Japan. He joined Nanjing University of Posts \& Telecommunications in 2008 . He was promoted as a full professor in 2010. His research area is organic optoelectronics, including the design, synthesis and excited-state tuning of organic semiconductors for applications in optoelectronic devices and biomedical fields.

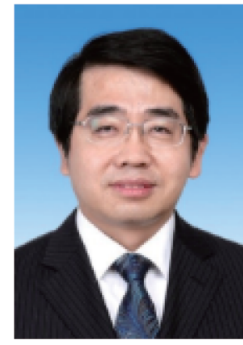

Wei Huang received his $\mathrm{PhD}$ degree from Peking University in 1992 and carried out postdoctoral research in the National University of Singapore. In 2001, he was appointed as a chair professor at Fudan University, where he founded and chaired the Institute of Advanced Material. His research interests include the synthesis, structures, and performance of organic/flexible optoelectronic materials and devices.

\section{寿命可调的有机室温磷光材料实现大面积安全打印}

余鹏飞 ${ }^{1}$, 秦妍妍 ${ }^{1}$, 马云 ${ }^{1^{*}}$, 李飞阳 ${ }^{1}$, 陆金玉 ${ }^{1}$, 戴佩伶 ${ }^{1}$, 胡豪 ${ }^{1}$, 刘向杰 ${ }^{1}$, 刘淑娟 ${ }^{1}$, 黄维 ${ }^{1,2 *}$, 赵强 ${ }^{1^{*}}$

摘要 有机室温磷光材料因其独特的光物理性质, 在安全记录和防 伪领域展现出了巨大的应用前景. 然而, 基于这类材料制备的防伪 图案或标签存在分辨低、安全性低、不易大面积加工等缺点, 极 大地限制了其大规模商业化应用. 本文设计、合成了一系列含不 同长度烷基链的有机膦盐来解决以上问题. 这类有机膦盐晶体中 存在较强的分子内/间相互作用, 使得它们具有高结晶能力, 因此 在经过研磨后仍然具有超长室温磷光. 此外, 通过改变烷基链长度 和卤素离子, 实现了室温磷光寿命的大范围调控(从 $1.27 \mathrm{~ms}$ 到 $884.71 \mathrm{~ms}$ ), 并利用商用喷墨打印机成功实现了多重信息加密和防伪. 